\title{
Prognostic Significance of PD-L1 and mTOR Expression in Oral Squamous Cell Carcinoma
}

\author{
Nattinee Charoen, M.D. ${ }^{1}$, Kitti Jantharapattana, M.D. ${ }^{2}$, Paramee Thongsuksai, M.D. ${ }^{1}$ \\ 'Department of Pathology, Faculty of Medicine, Prince of Songkla University, Hat Yai, Songkhla 90110, Thailand. \\ ${ }^{2}$ Department of Otolaryngology Head and Neck Surgery, Faculty of Medicine, Prince of Songkla University, Hat Yai, Songkhla \\ 90110, Thailand. \\ Received 15 February 2020 • Revised 2 April 2020 • Accepted 14 April 2020 • Published online 2 June 2020
}

\begin{abstract}
:
Objective: Programmed cell death ligand 1 (PD-L1) and mammalian target of rapamycin (mTOR) are key players in host immune evasion and oncogenic activation, respectively. Evidence of the prognostic role in oral squamous cell carcinoma (OSCC) is conflicting. This study examined the associations of PD-L1 and mTOR expression with 5-year overall survival in OSCC patients.
\end{abstract}

Material and Methods: The expressions of PD-L1 and mTOR proteins were immunohistochemically evaluated on tissue microarrays of 191 patients with OSCC who were treated by surgery at Songklanagarind Hospital, Thailand from 2008 to 2011. Cox regression analysis was used to determine independent prognostic factors.

Results: PD-L1 expression was observed in $14.1 \%$ of cases while mTOR expression was present in $74.3 \%$ of cases. Females were more likely to have tumors with PD-L1 ( $p$-value=0.007) and mTOR expressions $(p-v a l u e=0.003)$ than males. In addition, lower clinical stage and well differentiated tumor are more likely to have mTOR expression ( $p$-value= 0.038 and $p$-value<0.001, respectively). Cox regression analysis showed that age, tumor stage, nodal stage, combined surgical treatment with radiation or chemoradiation therapy, surgical margin status, PD-L1 expression and mTOR expression are independent prognostic factors. High PD-L1 expression (hazard ratio (HR) 3.14, 95\% confidence interval $(\mathrm{Cl}), 1.26-7.79)$ and high mTOR expression ( $\mathrm{HR} 1.69,95 \% \mathrm{Cl}, 1.00-2.84)$ are strong predictors of poor outcome. Conclusion: A proportion of OSCC expressed PD-L1 and mTOR proteins. Expression of PD-L1 and mTOR proteins are strong prognostic factors of OSCC.

Keywords: oral squamous cell carcinoma, PD-L1, mTOR, prognosis

Contact: Assoc. Prof. Paramee Thongsuksai, M.D.

Department of Pathology, Faculty of Medicine, Prince of Songkla University,

Hat Yai, Songkhla 90110, Thailand.

E-mail: tparamee@gmail.com

() 2020 JHSMR. Hosting by Prince of Songkla University. All rights reserved.

This is an open access article under the CC BY-NC-ND license

(http://www.jhsmr.org/index.php/jhsmr/about/editorialPolicies\#openAccessPolicy).
J Health Sci Med Res 2020;38(4):255-266 doi: $10.31584 /$ jhsmr.2020745 www.jhsmr.org 


\section{Introduction}

Cancer of the oral cavity is one of the common malignancies worldwide with an estimated 354,864 new cases and 177,384 deaths in 2018. ${ }^{1}$ The incidence is varied in different countries, being higher in low socioeconomic countries. In Thailand, the age-standardized rate of oral cancer $(9.1$ per 100,000$)$ is higher in the southern region than in other regions. ${ }^{2}$ The majority of oral cancer is squamous cell carcinoma. Surgery and radiation and adjuvant chemotherapy significantly improve survival rates in the early stage. ${ }^{2}$ However, the prognosis is still poor and 5-year overall survival rate is up to $60.0 \%$ in advanced stage., ${ }^{3,4}$ Chemoradiation therapy is, however, associated with high morbidity. Currently, novel immune and targeted therapies including programmed cell death ligand 1 (PD-L1) and mammalian target of rapamycin (mTOR) inhibitors are being investigated in many cancer types. $^{5,6}$ Thus, evaluation of PD-L1 and mTOR expression and their prognostic significances are important in the provision of information on the potential benefits from the usage of these novel therapies.

PD-L1, a cell surface molecule, is a key player in the immune suppression pathway. Under physiologic conditions, PD-L1 ligand on antigen-presenting cells binds to the programmed death-ligand 1 receptor on activated $\mathrm{T}$ cells, leading to reduced proliferation of antigenspecific T cell. ${ }^{7}$ This mechanism plays an important role in self-tolerance along with protection against autoimmunity. However, various tumor cell types can express PD-L1, enabling them to evade immune detection and therefore, elimination. ${ }^{8}$ For clinical utility, the effectiveness of blocking agents against PD-L1 is being evaluated, and has shown a promising result. ${ }^{9} \mathrm{PD}-\mathrm{L} 1$ expression on tumor cells has been found to be related with poor prognosis in many cancer types. ${ }^{10-12}$ However, reports of prognostic significance in oral squamous cell carcinoma (OSCC) are controversial. ${ }^{13-16}$
mTOR protein is a key downstream molecule of the phosphatidylinositol-3-kinase (PI3K)/Akt/mTOR pathway which involves in various cellular functions including cell proliferation, survival, and motility. ${ }^{17}$ mTOR is frequently upregulated in many cancers and is related to poor prognosis, ${ }^{18,19}$ However, clinical trials have shown only modest objective response rates, and so a combination of targeted therapeutic agents has been suggested as an alternative possibility. ${ }^{20,21}$ Nevertheless, simultaneous evaluation of PD-L1 and mTOR expression in tumors with regards to clinical outcomes has rarely been reported. Therefore, this study aimed to examine the association of PD-L1 and mTOR protein expressions with 5-year overall survival (OS) in surgically resected OSCC patients.

\section{Material and Methods}

This cohort of patients had been included in our previous study. ${ }^{22}$ They were patients who were diagnosed of OSCC and treated by surgery at Songklanagarind Hospital, Thailand, from January 2008 to December 2011. The Human Ethics Committee of the Faculty of Medicine approved our study protocol (REC. 59-295-0501). Clinical data, lifestyle habits (smoking and alcohol drinking) and pathological information were retrieved from medical records and pathological reports. The patients were staged using the tumor, node, and metastasis (TNM) staging system, according to the guideline of the American Joint Committee on Cancer, $7^{\text {th }}$ edition, 2010. Date of death was acquired from the civil registration system

Treatments given to the patients were of curative intent. The decision on individual treatment resulted from multidisciplinary tumor board recommendations, which were on the oncologic principles of oral cancer treatment. For the early stage, a single treatment modality, such as surgery, was given primarily. If there was an adverse pathological result such as lymphovascular invasion or 
inadequate resection of the primary tumor, adjuvant radiation or chemoradiation was administrated. For advanced stages, a combined treatment modality was applied. Adjuvant chemoradiation using a Platinum-based regimen was indicated in cases of incomplete resection margins and/or extranodal extensions. Patients were deemed to have local tumor recurrence if a histologically proven cancer reappeared at the site of first occurrence after completion of treatment for 6 months.

\section{Tissue microarray (TMA) construction}

TMAs were constructed as previously described. ${ }^{22}$ Briefly, the histologic slides were reviewed, then, the area having abundant viable tumor cells were circled. Then, the corresponding areas on the paraffin-embedded tissue blocks were outlined with a felt tip marker. A TMA having two 2-mm cores from each case was constructed using Quick Ray ${ }^{\circledR}$ manual tissue microarrayer (Unitma, Seoul, Korea)

\section{Immunuhistochemistry and staining evaluation}

Immunohistochemistry for PD-L1 expression was performed in EnVision FLEX visualization system on Autostainer Link 48 (Dako, California, United States of America). The 3- $\mu$ m-thick sections were deparaffinized with xylene and rehydrated in graded alcohol. Antigen was retrieved via PT Link (Dako PT109) using EnVision ${ }^{\text {TM }}$ FLEX Target Retrieval Solution according to manufacturer's instruction. Following FLEX peroxidase blocking for 5 minutes, the sections were incubated with primary antibodies against PD-L1 (monoclonal mouse anti-PD-L1, clone 22C3, Dako). Diaminobenzidine (DAB) was used as a chromogen for color development. The slides were then counterstained by EnVision FLEX hematoxylin (Code K8008).

Immunohistochemistry for mTOR expression was performed in an automated immunostainer (Leica BOND-
MAX, Melbourne, Australia). Antigens were retrieved in the Tris-EDTA buffer (Bond Epitope Retrieval Solution 2, Leica Biosystem, Newcastle Upon Tyne, United Kingdom), $\mathrm{pH} 9$, in a pressure cooker at $95^{\circ} \mathrm{C}$ for 4 mins. The sections were then incubated with bond peroxidase-blocking reagent (Bond Polymer Refine Detection, Leica Biosystem, Newcastle Upon Tyne, United Kingdom). The sections were then incubated with primary antibodies against mTOR (polyclonal PAB26759, Abnova; dilution 1:50). Antibody reactions were detected by use of a bond polymer refine detection kit (Leica) and visualized by the methods described above.

Immunostaining was independently evaluated under light microscope (Olympus CX41) by N.C. and P.T. who did not know the patients' outcome at the time of evaluation; whereas in discordant cases, a consensus was achieved by discussion. The tissue core contained less than $10.0 \%$ of viable tumor cells were not evaluated. PD-L1 expression was evaluated according to the manufacturer protocol by using a Tumor Proportion Score (TPS), this being the percentage of tumor cells showing partial or complete membrane staining at any intensity. The cases were considered to have a low PD-L1 expression if TPS was $1.0-49.0 \%$ or a high PD-L1 expression if the TPS $\geq$ $50.0 \%$. For mTOR expression, the total immunoreactivity score was determined by multiplication of intensity score (0-3) by the percentage of positive stained tumor cells. mTOR expression was categorized into three groups according to the quartile values as: negative expression (score $\leq 15$ ), low expression (15 < score $\leq 60$ ) and high expression $\left(3^{\text {rd }} \& 4^{\text {th }}\right.$ quartile, score $\left.>60\right)$.

Percentages for categorical variables and mean for continuous variable are presented as descriptive statistics. Relationship between clinicopathological characteristics and protein expressions were assessed by chi-square or Fisher's exact test as appropriate. OS time was interval from date of diagnosis to date of death from any cause 
or to date of last follow-up. Censored observations were defined as patients who were alive at the time of last follow-up (June 2016). Kaplan-Meier survival probability was estimated and the difference among the survival curves was tested by log-rank test. The Cox proportion hazard model was used to evaluate independent prognostic parameters. P-value less than 0.05 was set as statistical significance. Intercooled Stata 6.0 was used an analysis software.

\section{Results}

\section{Patients' characteristics}

A total of 191 cases from 202 eligible patients had adequate tissues for immunohistochemistry assessment. Table 1 presents the clinical and pathological characteristics of the patients. The mean age of the patients was 61 years. Less than half of the cases (45.5\%) were stage I-II disease. The highest number of patients (49.7\%) was treated by surgical resection with post-operative radiotherapy, $33.0 \%$ were treated by surgical resection alone, and $17.3 \%$ by surgery coupled with chemoradiation therapy.

\section{Protein expressions and association with} clinicopathological characteristics

Two tissue cores were examined in 178 cases and only one core in 13 cases (nine cores of tissue loss and four cores of inadequate tumor cells). PD-L1 expression was noted as membrane staining and mTOR expression as cytoplasmic and membrane staining (Figure 1). The majority of cases $(164,85.9 \%)$ showed negative PD-L1 expression and 19 (9.9\%) and 8 (4.2\%) cases showed low and high PD-L1 expressions, respectively. The median total score of mTOR immunoreactivity was 60 (interquartile range 15,120$)$. Negative, low and high mTOR expression was noted in 49 (26.7\%), 47 (24.6\%) and 95 $(49.7 \%)$ tumors, respectively.

Table 1 Clinicopathological characteristics of 191 oral cancer patients

\begin{tabular}{|c|c|c|}
\hline Variables & Category & Number (\%) \\
\hline \multirow[t]{2}{*}{ Gender } & Female & $69(36.1)$ \\
\hline & Male & $122(63.9)$ \\
\hline \multirow[t]{2}{*}{ Age (years) } & $\leq 65$ & $113(59.2)$ \\
\hline & $>65$ & $78(40.8)$ \\
\hline \multirow[t]{3}{*}{ Smoking } & Never & $64(33.5)$ \\
\hline & Habitual & 103 (53.9) \\
\hline & Unknown & $24(12.6)$ \\
\hline \multirow[t]{3}{*}{ Alcohol drinking } & Never/social & $81(42.4)$ \\
\hline & Habitual & $78(40.8)$ \\
\hline & Unknown & $32(16.7)$ \\
\hline \multirow[t]{5}{*}{ Tumor site } & Tongue & $91(47.6)$ \\
\hline & Floor of mouth & $34(17.8)$ \\
\hline & Gum & $22(11.5)$ \\
\hline & Buccal mucosa & $21(11.0)$ \\
\hline & Others & $23(12.0)$ \\
\hline \multirow[t]{2}{*}{$\mathrm{T}$ stage } & $\mathrm{T} 1-\mathrm{T} 2$ & $114(59.7)$ \\
\hline & T3-T4 & 77 (40.3) \\
\hline \multirow[t]{2}{*}{$\mathrm{N}$ stage } & NO & $129(67.5)$ \\
\hline & $\mathrm{N} 1-\mathrm{N} 3$ & $62(32.5)$ \\
\hline \multirow[t]{4}{*}{ Clinical staging } & I & 35 (18.3) \\
\hline & II & $52(27.2)$ \\
\hline & III & $30(15.7)$ \\
\hline & IV & $74(38.7)$ \\
\hline \multirow[t]{3}{*}{ Treatment } & Surgery alone & $63(33.0)$ \\
\hline & Surgery + RT & $95(49.7)$ \\
\hline & Surgery + CCRT & $33(17.3)$ \\
\hline \multirow[t]{2}{*}{ Tumor recurrence } & No & $165(86.4)$ \\
\hline & Yes & $26(13.6)$ \\
\hline \multirow[t]{3}{*}{ Tumor differentiation } & Well & $142(74.3)$ \\
\hline & Moderate & $43(22.5)$ \\
\hline & Poor & $6(3.1)$ \\
\hline \multirow[t]{2}{*}{ Surgical margin status } & Free of tumor & $157(82.2)$ \\
\hline & With tumor & $34(17.8)$ \\
\hline \multirow[t]{2}{*}{ Lymphovascular invasion } & Absence & $177(92.7)$ \\
\hline & Presence & $14(7.3)$ \\
\hline \multirow[t]{2}{*}{ Perineural invasion } & Absence & $173(90.6)$ \\
\hline & Presence & $18(9.4)$ \\
\hline
\end{tabular}

$\mathrm{RT}$ =radiotherapy, CCRT=concurrent chemoradiation therapy 

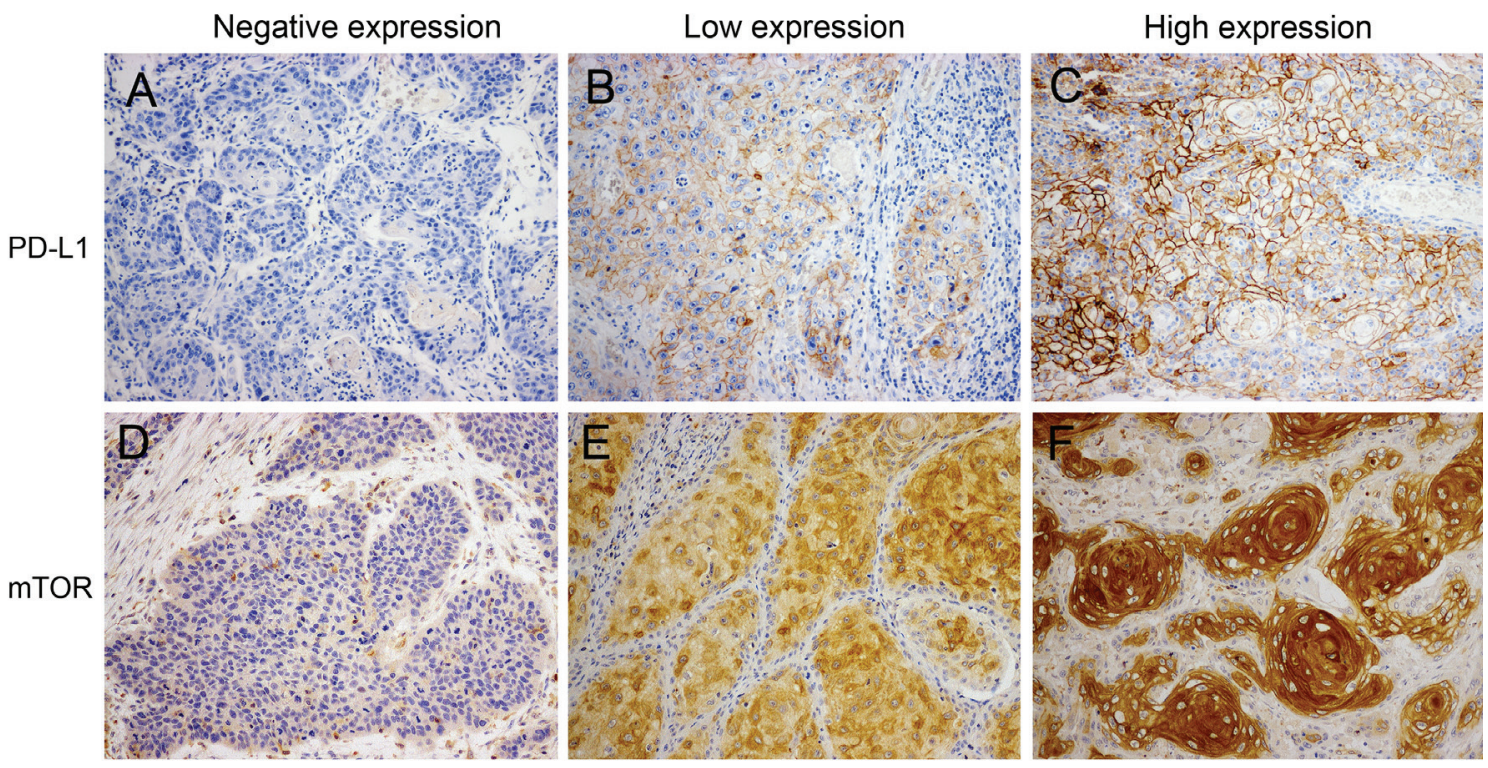

Figure 1 Immunohistochemical staining of the representative cases for PD-L1 expression; negative (A), low (B) and high expression (C) and for mTOR expression; negative (D), low (E) and high expression (F) Original magnification, $200 x$

The association of PD-L1 and mTOR expressions is shown in Table 2 and Table 3, respectively. Due to the small number of cases, low and high PD-L1 expressions were grouped as positive PD-L1 expression. Only gender was associated with PD-L1 expression while gender, clinical stage and tumor differentiation were associated with mTOR expression. Females were more likely to have tumor with PD-L1 and mTOR expressions than males. High mTOR expression was seen more frequently found in lower clinical stage and well-differentiated tumor. The remaining clinical variables were not found to be associated with either PD-L1 or mTOR expressions.

\section{Association of PD-L1 and mTOR expression}

\section{with 5-year overall survival}

Median survival time was 49.8 months (range 3.1 to 101.5 months). The 5 -year OS was $45.5 \%$ (95\% confidence interval $(\mathrm{Cl}), 38.3-52.4)$. Figure 2 shows the
Kaplan-Meier curves stratified by PD-L1 and mTOR expression level. Increased level of PD-L1 expression was associated with poorer survival $(p-$ value=0.055), while mTOR expression level showed no difference of survival probability ( $p$-value $=0.134$ ).

Results of Cox regression analyses are shown in Table 4. Age, $\mathrm{T}$ stage, $\mathrm{N}$ stage, treatment and PD-L1 expression were significantly associated with poor survival in univariate analysis. In multivariable analysis, all of these five factors and two additional variables including surgical margin and mTOR expression were significant prognostic factors. Both PD-L1 and mTOR expression were associated with poorer prognosis compared to negative expression. In addition, increasing level of PD-L1 expression was associated with worsening prognosis in stepwise manner [low PD-L1, HR 1.87 (95\% Cl, 1.033.38); high PD-L1, HR 3.14 (95\% Cl, 1.26-7.79)]. We did not evaluate combined expression of both proteins, as the amount of positive PD-L1 was too limited. 
Table 2 Association of PD-L1 expression with clinicopathological variables in 191 oral cancer patients

\begin{tabular}{|c|c|c|c|}
\hline \multirow{3}{*}{ Variables } & \multicolumn{2}{|c|}{ PD-L1 expression } & \multirow{3}{*}{ p-value } \\
\hline & Negative & Positive & \\
\hline & Number (\%) & Number (\%) & \\
\hline \multicolumn{4}{|l|}{ Age (years) } \\
\hline$\leq 65$ & $98(59.8)$ & $15(55.6)$ & 0.681 \\
\hline$>65$ & $66(40.2)$ & $12(44.4)$ & \\
\hline \multicolumn{4}{|l|}{ Gender } \\
\hline Male & $111(67.7)$ & $11(40.7)$ & 0.007 \\
\hline Female & $53(32.3)$ & $16(59.3)$ & \\
\hline \multicolumn{4}{|l|}{ Smoking } \\
\hline Never & $57(34.8)$ & $7(25.9)$ & 0.660 \\
\hline Habitual & $87(53.0)$ & $16(59.3)$ & \\
\hline Unknown & $20(12.2)$ & $4(14.8)$ & \\
\hline \multicolumn{4}{|l|}{ Alcohol drinking } \\
\hline Never & $70(42.7)$ & $11(40.7)$ & 0.909 \\
\hline Habitual & $66(49.2)$ & $12(44.4)$ & \\
\hline Unknown & $28(17.1)$ & $4(14.8)$ & \\
\hline \multicolumn{4}{|l|}{ T stage } \\
\hline $\mathrm{T} 1-\mathrm{T} 2$ & $99(60.4)$ & $15(55.6)$ & 0.637 \\
\hline T3-T4 & $65(39.6)$ & $12(44.4)$ & \\
\hline \multicolumn{4}{|l|}{ N stage } \\
\hline NO & $110(67.1)$ & $19(70.4)$ & 0.735 \\
\hline N1-N3 & $54(32.9)$ & $8(29.6)$ & \\
\hline \multicolumn{4}{|l|}{ Clinical staging } \\
\hline$|-| \mid$ & $76(46.3)$ & $11(40.7)$ & 0.588 \\
\hline III-IV & $88(53.7)$ & $16(59.3)$ & \\
\hline \multicolumn{4}{|l|}{ Treatment } \\
\hline Surgery & 53 (32.3) & $10(37.1)$ & 0.573 \\
\hline Surgery + RT & $84(51.2)$ & $11(40.7)$ & \\
\hline Surgery + CCRT & $27(16.5)$ & $6(22.2)$ & \\
\hline \multicolumn{4}{|l|}{ Tumor differentiation } \\
\hline Well & $123(75.0)$ & $19(70.4)$ & 0.610 \\
\hline Moderate-poor & $41(25.0)$ & $8(29.6)$ & \\
\hline \multicolumn{4}{|l|}{ Surgical margin } \\
\hline Free of tumor & $134(81.7)$ & $23(85.2)$ & 0.662 \\
\hline With tumor & $30(18.3)$ & $4(14.8)$ & \\
\hline \multicolumn{4}{|c|}{ Lymphovascular invasion } \\
\hline Absence & $152(92.7)$ & $25(92.6)$ & 0.987 \\
\hline Presence & $12(7.3)$ & $2(7.4)$ & \\
\hline \multicolumn{4}{|l|}{ Perineural invasion } \\
\hline Absence & $149(90.9)$ & $24(88.9)$ & 0.746 \\
\hline Presence & $15(9.1)$ & $3(11.1)$ & \\
\hline
\end{tabular}

PD-L1=programmed cell death ligand 1, RT=radiotherapy, CCRT=concurrent chemoradiation therapy 
Table 3 Association of mTOR expression with clinicopathological variables

\begin{tabular}{|c|c|c|c|c|}
\hline \multirow{3}{*}{ Variables } & \multicolumn{3}{|c|}{ mTOR expression } & \multirow{3}{*}{$p$-value } \\
\hline & Negative & Low & High & \\
\hline & Number (\%) & Number (\%) & Number (\%) & \\
\hline \multicolumn{5}{|l|}{ Age (years) } \\
\hline$\leq 65$ & $30(61.2)$ & $26(55.3)$ & $57(60.0)$ & \multirow[t]{2}{*}{0.818} \\
\hline$>65$ & 19 (38.88) & $21(44.7)$ & $38(40.0)$ & \\
\hline \multicolumn{5}{|l|}{ Gender } \\
\hline Male & $41(83.7)$ & $29(61.7)$ & $52(54.7)$ & \multirow[t]{2}{*}{0.003} \\
\hline Female & $8(16.3)$ & $18(38.3)$ & $43(45.3)$ & \\
\hline \multicolumn{5}{|l|}{ Smoking } \\
\hline Never & $12(24.5)$ & $19(40.4)$ & $33(34.8)$ & \multirow[t]{3}{*}{0.529} \\
\hline Habitual & $31(63.3)$ & $22(46.8)$ & $50(52.6)$ & \\
\hline Unknown & $6(12.2)$ & $6(12.8)$ & $12(12.6)$ & \\
\hline \multicolumn{5}{|l|}{ Alcohol drinking } \\
\hline Never & $16(32.6)$ & $19(40.4)$ & $46(48.4)$ & \multirow[t]{3}{*}{0.117} \\
\hline Habitual & $26(53.1)$ & $22(46.8)$ & $30(31.6)$ & \\
\hline Unknown & 7 (14.3) & $6(12.8)$ & $19(20.0)$ & \\
\hline \multicolumn{5}{|l|}{$\mathrm{T}$ stage } \\
\hline $\mathrm{T} 1-\mathrm{T} 2$ & $28(57.1)$ & $25(53.2)$ & $61(64.2)$ & \multirow[t]{2}{*}{0.414} \\
\hline T3-T4 & $21(42.9)$ & $22(46.8)$ & $34(35.8)$ & \\
\hline \multicolumn{5}{|l|}{$\mathrm{N}$ stage } \\
\hline No & $27(55.1)$ & $31(65.9)$ & $71(74.7)$ & \multirow[t]{2}{*}{0.056} \\
\hline N1-N3 & $22(44.9)$ & $16(34.1)$ & $24(25.3)$ & \\
\hline \multicolumn{5}{|l|}{ Clinical staging } \\
\hline$|-| \mid$ & $17(34.7)$ & $18(38.3)$ & $52(54.7)$ & \multirow[t]{2}{*}{0.038} \\
\hline III-IV & $32(65.3)$ & $29(61.7)$ & $43(45.3)$ & \\
\hline \multicolumn{5}{|l|}{ Treatment } \\
\hline Surgery & $13(26.5)$ & $13(27.7)$ & 37 (38.9) & \multirow[t]{3}{*}{0.183} \\
\hline Surgery + RT & $25(51.0)$ & $29(61.7)$ & $41(43.2)$ & \\
\hline Surgery + CCRT & $11(22.5)$ & $5(10.6)$ & $17(17.9)$ & \\
\hline \multicolumn{5}{|l|}{ Tumor differentiation } \\
\hline Well & $22(44.9)$ & $35(74.5)$ & $85(89.5)$ & \multirow[t]{2}{*}{$<0.001$} \\
\hline Moderate-poor & $27(55.1)$ & $12(25.5)$ & $10(10.5)$ & \\
\hline \multicolumn{5}{|l|}{ Surgical margin } \\
\hline Free of tumor & $36(73.5)$ & $37(78.7)$ & $84(88.4)$ & \multirow[t]{2}{*}{0.065} \\
\hline With tumor & $13(26.5)$ & $10(21.3)$ & $11(11.6$ & \\
\hline \multicolumn{5}{|c|}{ Lymphovascular invasion } \\
\hline Absence & $44(89.8)$ & $43(91.5)$ & $90(94.7)$ & \multirow[t]{2}{*}{0.525} \\
\hline Presence & $5(10.2)$ & $4(8.5)$ & $5(5.3)$ & \\
\hline \multicolumn{5}{|l|}{ Perineural invasion } \\
\hline Absence & $44(89.8)$ & $40(85.1)$ & $89(93.7)$ & 0.252 \\
\hline Presence & $5(10.2)$ & 7 (14.9) & $6(6.3)$ & \\
\hline
\end{tabular}

mTOR=mammalian target of rapamycin, $\mathrm{RT}=$ radiotherapy, CCRT=concurrent chemoradiation therapy 
Table 4 Univariate and multivariate cox regression for overall survival of oral cancer patients

\begin{tabular}{|c|c|c|c|c|}
\hline \multirow{2}{*}{ Variables } & \multicolumn{2}{|c|}{ Univariate analysis } & \multicolumn{2}{|c|}{ Multivariate analysis } \\
\hline & Crude HR $(95 \% \mathrm{Cl})$ & $p$-value & Adjusted HR $(95 \% \mathrm{Cl})$ & p-value \\
\hline \multicolumn{5}{|l|}{ Age (years) } \\
\hline$\leq 65$ & 1 & & 1 & \\
\hline$>65$ & $1.59(0.09-2.31)$ & 0.015 & $2.64(1.68-4.16)$ & $<0.001$ \\
\hline \multicolumn{5}{|l|}{ Sex } \\
\hline Male & 1 & & & \\
\hline Female & $1.35(0.92-1.97)$ & 0.122 & & \\
\hline \multicolumn{5}{|l|}{ Smoking } \\
\hline Never & 1 & & & \\
\hline Habitual & $1.25(0.83-1.89)$ & 0.279 & & \\
\hline Unknown & $0.87(0.46-1.65)$ & 0.672 & & \\
\hline \multicolumn{5}{|l|}{ Alcohol drinking } \\
\hline \multicolumn{5}{|l|}{ Never } \\
\hline Habitual & $1.31(0.88-1.96)$ & 0.177 & & \\
\hline Unknown & $0.77(0.43-1.35)$ & 0.358 & & \\
\hline \multicolumn{5}{|l|}{ T stage } \\
\hline $\mathrm{T} 1-\mathrm{T} 2$ & 1 & & 1 & \\
\hline T3-T4 & $2.86(1.95-4.18)$ & 0.000 & $1.97(1.28-3.04)$ & 0.002 \\
\hline \multicolumn{5}{|l|}{$\mathrm{N}$ stage } \\
\hline No & 1 & & 1 & \\
\hline $\mathrm{N} 1$ & $1.98(1.19-3.29)$ & 0.012 & $2.41(1.36-4.29)$ & 0.003 \\
\hline N2-N3 & $1.84(1.15-2.96)$ & 0.648 & $1.71(1.02-2.84)$ & 0.041 \\
\hline \multicolumn{5}{|l|}{ Treatment } \\
\hline Surgery & 1 & & 1 & \\
\hline Surgery + RT & $3.06(1.89-4.96)$ & 0.000 & $2.64(1.53-4.56)$ & 0.033 \\
\hline Surgery + CCRT & $2.58(1.42-4.70)$ & 0.002 & $2.19(1.07-4.51)$ & $<0.001$ \\
\hline \multicolumn{5}{|l|}{ Differentiation } \\
\hline Well & 1 & & & \\
\hline Moderate-poor & $1.11(0.72-1.69)$ & 0.648 & & \\
\hline \multicolumn{5}{|l|}{ Surgical margin } \\
\hline Free of tumor & 1 & & 1 & \\
\hline With tumor & $1.34(0.84-2.16)$ & 0.222 & $2.09(1.19-3.66)$ & 0.011 \\
\hline \multicolumn{5}{|c|}{ Lymphovascular invasion } \\
\hline Absence & 1 & & & \\
\hline Presence & $1.58(0.82-3.03)$ & 0.168 & & \\
\hline \multicolumn{5}{|l|}{ Perineural invasion } \\
\hline Absence & 1 & & & \\
\hline Presence & $1.08(0.57-2.08)$ & 0.802 & & \\
\hline \multicolumn{5}{|l|}{ PD-L1 expression } \\
\hline Negative & 1 & & 1 & \\
\hline Low & $1.49(0.85-2.62)$ & 0.166 & $1.87(1.03-3.38)$ & 0.038 \\
\hline High & $2.35(1.03-5.37)$ & 0.044 & $3.14(1.26-7.79)$ & 0.014 \\
\hline \multicolumn{5}{|l|}{ mTOR expression } \\
\hline Negative & 1 & & 1 & \\
\hline Low & $1.56(0.93-2.59)$ & 0.091 & $1.98(1.15-3.41)$ & 0.014 \\
\hline High & $1.06(0.65-1.73)$ & 0.831 & $1.69(1.00-2.84)$ & 0.049 \\
\hline
\end{tabular}

$\mathrm{HR}=$ hazard ratio, $\mathrm{Cl}=$ confidence interval, $\mathrm{RT}=$ radiotherapy, $\mathrm{CCRT}=$ concurrent chemoradiation therapy, $\mathrm{PD}-\mathrm{L} 1=$ programmed cell death ligand 1, mTOR=mammalian target of rapamycin 
A Kaplan-Meier survival estimates by PD-L1 expression

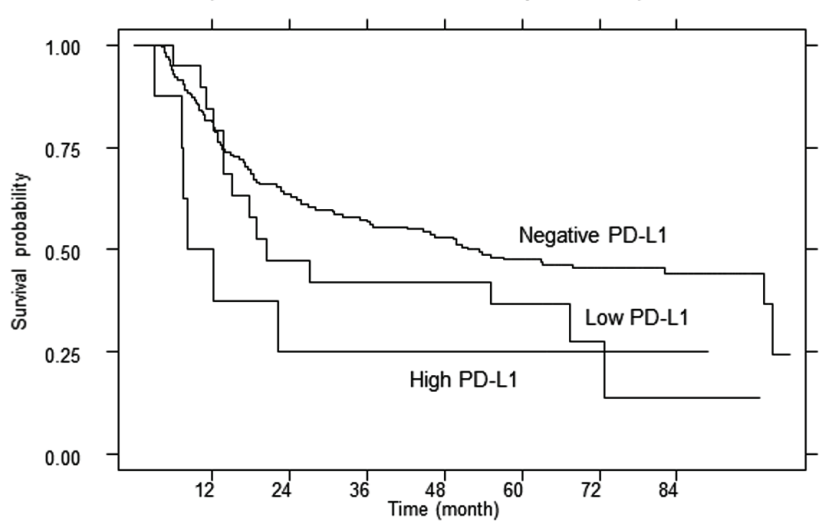

B Kaplan-Meier survival estimates by mTOR expression

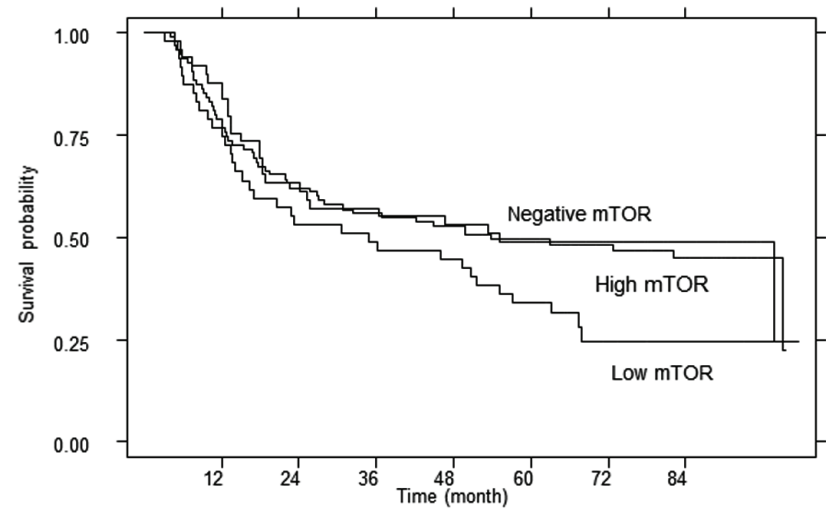

Figure 2 Kaplan-Meier curves of overall survival in patients with oral squamous cell carcinoma according to PD-L1 (A) and mTOR expression (B)

\section{Discussion}

Capabilities of immune evasion as well as enhancing proliferative signaling are two important hallmarks of cancer that enable tumor development, progression and dissemination. PD-L1 and mTOR are, respectively, key players in these two processes. In this study, we found that $14.0 \%$ of OSCC expressed PD-L1 and $74.3 \%$ expressed mTOR protein. In addition, tumors with PD-L1 or mTOR expression were significantly associated with poor prognosis.

We found $14.0 \%$ of tumors expressed PD-L1, while other studies reported a frequency of $46.0-87.0 \%{ }^{13,15,16,23,24}$ These conflicting results may be due to various factors, including patient characteristics and immunohistochemistry technique. Hanna et al. ${ }^{16}$ confined their study to young patients aged $\leq 45$ years and Kogashiwa et al. ${ }^{15}$ included patients with advanced disease (stage III-IVa). By contrast, we included patients of any age and any stage, and nearly half of them were stage I-II. Regarding immunohistochemistry, various antibodies (monoclonal and polyclonal) and scoring strategies of PD-L1 expression were applied. We used PD-L1 22C3 pharmDx which is a FDA-approved diagnostic antibody used for selecting lung cancer patients for anti-PD-L1 therapy. ${ }^{9}$ This antibody and its evaluation criteria have been reported to have a high inter-observer reproducibility. ${ }^{25}$ By contrast, Ngamphaiboon et al. $^{24}$, who also studied in Thai patients, used SP142 assay in 203 head and neck squamous cell carcinoma (HNSCC) and found a very high (80.0\%) PD-L1 expression.

Prognostic role of PD-L1 expression in OSCC or HNSCC have been reported. However, many studies have not found the significant association of PD-L1 with survival outcome. ${ }^{13,23,26}$ Besides, some studies reported a better survival in OSCC with PD-L1 expression ${ }^{15,27,28}$ which is reverse to the functional roles of PD-L1 as immune invader and tumor enhancer. A pooled analysis of these studies reported in the form of meta-analysis shows nonsignificant results ( $\mathrm{HR} 0.60,95 \% \mathrm{Cl} 0.33-1.10)$ with a high rate of heterogeneity among studies. ${ }^{29}$ All of these studies except of Lin et al. ${ }^{13}$ have a small number of study subjects (less than 100). By contrast, our study found that either low or high PD-L1 expressions were significantly related to poor survival in OSCC. High PD-L1 showed comparable or even stronger prognostic factors as compared to nodal stage which is a well-known strong predictor. Our results are consistent with the studies by Moratin et al. ${ }^{30}$ and 
Ngamphaiboon et al. $^{24}$, both of which have included a considerable large sample size $(n=175$ and $n=203$, respectively. The latter study is also from Thailand, performed in a tertiary hospital in the central part of the country.

Most HNSCC are found to have an activated $\mathrm{PI3K} / \mathrm{Akt} / \mathrm{mTOR}$ signaling pathway. ${ }^{17,31}$ Based on recent meta-analysis in 12 studies of HNSCC, the frequency of expression of the pathway proteins stands at $74.4 \%$ $\left(95 \% \mathrm{Cl}\right.$ 63.3-84.0)..$^{19,32}$ Consistent with this, our study also found that the majority of cases $(70.0 \%)$ expressed an mTOR protein which is slightly higher than previous studies (range 53.0-64.0\%). ${ }^{33,34}$ This discrepancy may be due to the different clonality of antibodies and/or different expression scoring systems. We used polyclonal antibodies, coupled with an $\mathrm{H}$-score system, while Monteiro et al. $^{33}$ used monoclonal antibody and a summation of intensity and percentage of positive tumor cells.

In our study, low mTOR expression was related to higher clinical stage. Besides, based on Kaplan-Meier curves, low mTOR expression group seems to have poorer survival than the high expression group, although it was not statistically significant. This is inconsistent with the theoretical expectation, as mTOR activation is likely to be associated with aggressive tumor behavior. As known, mTOR is one of the protein kinases in PI3K/AKT signaling pathway which interacts with many upstream and downstream molecules. The aforementioned relationship between mTOR and clinical stage, may therefore, be influenced by other molecules of the related pathways.

Regarding the association of mTOR expression and survival in OSCC, the Kaplan-Meier analysis and log rank test demonstrated no significant association of mTOR expression with overall survival ( $p$-value=0.134). However, mTOR expression turns to be an independent prognostic factor in multivariate analysis. This is likely because the confounding effect on the relationship between mTOR and survival had been eliminated. The confounder here is likely to be clinical stage and nodal stage, as shown in Table 3 where these two variables are significantly associated with mTOR expression. We also performed subgroup analysis stratified by clinical stage - another strategy to determine confounder. The results showed significant $\mathrm{HR}$ of mTOR expression in stage III-IV group, but not in stage I-II group (data not shown). Our multivariate results are consistent with other authors, which reported that mTOR expression is significantly increased risk of death (HRs were $2.19^{33}$ and $2.08^{35}$ ). Therefore, our study supports the importance of the mTOR pathway in the progression of OSCC.

Certain limitations have to be noted in this study. The retrospective nature of the study may have made it subject to selection and/or follow-up bias. In addition, we included patients who treated by surgical resection, and thus may have under-represented patients who could not tolerate surgical resection. Another important limitation is that we did not evaluate the prognostic role of combined PD-L1 and mTOR expression as the number of cases in each combined category was too small.

\section{Conclusion}

In summary, a proportion of OSCC expressed PDL1 and mTOR proteins. PD-L1 and mTOR expressions were strong independent prognostic predictors in OSCC. These results may provide preliminary evidence for the potential benefit of novel therapy against PD-L1 and PI3K/Ark/mTOR pathway in the treatment of OSCC.

\section{Acknowledgement}

This work was funded by Faculty of Medicine, Prince of Songkla University, Thailand. Cancer registry unit, Songklanagarind Hospital was acknowledged for providing the registry data. 


\section{Conflict of interest}

All authors declare there is no conflict of interest.

\section{References}

1. Bray F, Ferlay J, Soerjomataram I, Siegel RL, Torre LA, Jemal A. Global cancer statistics 2018: GLOBOCAN estimates of incidence and mortality worldwide for 36 cancers in 185 countries. CA Cancer J Clin 2018;68:394-424.

2. Carvalho AL, Ikeda MK, Magrin J, Kowalski LP. Trends of oral and oropharyngeal cancer survival over five decades in 3267 patients treated in a single institution. Oral Oncol 2004;40:71-6.

3. Pruegsanusak K, Peeravut S, Leelamanit V, Sinkijcharoencha W, Jongsatitpaiboon J, Phungrassami T. Survival and prognostic factors of different sites of head and neck cancer: an analysis from Thailand. Asian Pac J Cancer Prev 2012;13:885-90.

4. Chen TC, Hsu CW, Lou PJ, Ko JY, Yang TL, Chen CN, et al. The clinical predictive factors for subsequent distant metastasis in patients with locoregionally advanced oral squamous cell carcinoma. Oral Oncol 2013;49:367-73.

5. Brahmer JR, Tykodi SS, Chow LQ, Hwu WJ, Topalian SL, Hwu P, et al. Safety and activity of anti-PD-L1 antibody in patients with advanced cancer. N Engl J Med 2012;366: 2455-65.

6. Topalian SL, Hodi FS, Brahmer JR, Gettinger SN, Smith DC, McDermott DF, et al. Safety, activity, andimmune correlates of anti-PD-1 antibody in cancer. N Engl J Med 2012;366: 2443-54.

7. Riley JL. PD-1 signaling in primary T cells. Immunol Rev 2009; 229:114-25.

8. Sanmamed MF, Chen L. Inducible expression of B7-H1 (PD-L1) and its selective role in tumor site immune modulation. Cancer J 2014;20:256-61.

9. Sul J, Blumenthal GM, Jiang X, He K, Keegan P, Pazdur R. FDA approval summary: pembrolizumab for the treatment of patients with metastatic non-small cell lung cancer whose tumors express programmed death-ligand 1. Oncologist 2016; 21:643-50.

10. Muenst S, Schaerli AR, Gao F, Däster S, Trella E, Droeser $\mathrm{RA}$, et al. Expression of programmed deathligand 1 (PD-L1) is associated with poor prognosis in human breast cancer. Breast Cancer Res Treat 2014;146:15-24.

11. Leite KR, Reis ST, Junior JP, Zerati M, Gomes Dde O, Camara-
Lopes LH, et al. PD-L1 expression in renal cell carcinoma clear cell type is related to unfavorable prognosis. Diagn Pathol 2015; 10:189.

12. Zeng J, Zhang XK, Chen HD, Zhong ZH, Wu QL, Lin SX. Expression of programmed cell death-ligand 1 and its correlation with clinical outcomes in gliomas. Oncotarget 2016;7:8944-55.

13. Lin YM, Sung WW, Hsieh MJ, Tsai SC, Lai HW, Yang SM, et al. High PD-L1 expression correlates with metastasis and poor prognosis in oral squamous cell carcinoma. PLoS One 2015;10. doi: 10.1371/journal.pone.0142656.

14. Müller T, Braun M, Dietrich D, Aktekin S, Höft S, Kristiansen G, et al. PD-L1: a novel prognostic biomarker in head and neck squamous cell carcinoma. Oncotarget 2017;8:52889-900.

15. Kogashiwa $Y$, Yasuda $M$, Sakurai $H$, Nakahira $M$, Sano $Y$, Gonda K, et al. PD-L1 expression confers better prognosis in locally advanced oral squamous cell carcinoma. Anticancer Res 2017;37:1417-24.

16. Hanna GJ, Woo SB, Li YY, Barletta JA, Hammerman PS, Lorch JH. Tumor PD-L1 expression is associated with improved survival and lower recurrence risk in young women with oral cavity squamous cell carcinoma. Int $\mathrm{J}$ Oral Maxillofac Surg 2018;47:568-77.

17. Menon S, Manning BD. Common corruption of the mTOR signaling network in human tumors. Oncogene 2008;27 (Suppl 2):S43-51.

18. Ocana A, Vera-Badillo F, Al-Mubarak M, Templeton AJ, Corrales-Sanchez V, Diez-Gonzalez L, et al. Activation of the PI3K/mTOR/AKT pathway and survival in solid tumors: systematic review and meta-analysis. PLoS One 2014;9. doi: 10.1371/journal.pone.0095219.

19. Marques AE, Elias ST, Porporatti AL, Castilho RM, Squarize CH, De Luca Canto G, et al. mTOR pathway protein immunoexpression as a prognostic factor for survival in head and neck cancer patients: a systematic review and meta-analysis. J Oral Pathol Med 2016;45:319-28.

20. Meric-Bernstam F, Gonzalez-Angulo AM. Targeting the mTOR signaling network for cancer therapy. J Clin Oncol 2009;27: 2278-87.

21. Wang Z, Valera JC, Zhao X, Chen Q, Gutkind JS. mTOR co-targeting strategies for head and neck cancer therapy. Cancer Metastasis Rev 2017;36:491-502.

22. Wangmo C, Charoen N, Jantharapattana K, Dechaphunkul A, 
Thongsuksai P. Epithelial-mesenchymal transition predicts survival in oral squamous cell carcinoma. Pathol Oncol Res 2019. doi: 10.1007/s12253-019-00731-z.

23. Cho YA, Yoon HJ, Lee JI, Hong SP, Hong SD. Relationship between the expressions of PD-L1 and tumor-infiltrating lymphocytes in oral squamous cell carcinoma. Oral Oncol 2011; 47:1148-53.

24. Ngamphaiboon N, Chureemas T, Siripoon T, Arsa L, Trachu N, Jiarpinitnun $\mathrm{C}$, et al. Characteristics and impact of programmed death-ligand 1 expression, CD8+ tumor-infiltrating lymphocytes, and p16 status in head and neck squamous cell carcinoma. Med Oncol 2019;36:21.

25. Büttner R, Gosney JR, Skov BG, Adam J, Motoi N, Bloom KJ, et al. Programmed death-ligand 1 immunohistochemistry testing: a review of analytical assays and clinical implementation in non-small-cell lung cancer. J Clin Oncol 2017;35:386776.

26. Mattox AK, Lee J, Westra WH, Pierce RH, Ghossein R, Faquin WC, et al. PD-L1 expression in head and neck squamous cell carcinomas derives primarily from functionally anergic CD4(+) TILs in the presence of PD-L1 (+) TAMs. Cancer Res 2017;77: 6365-74.

27. Oliveira-Costa JP, de Carvalho AF, da Silveira da GG, Amaya $\mathrm{P}$, Wu Y, Park KJ, et al. Gene expression patterns through oral squamous cell carcinoma development: PD-L1 expression in primary tumor and circulating tumor cells. Oncotarget 2015; 6:20902-20.

28. Ahn $\mathrm{H}$, Yang JM, Kim H, Chung JH, Ahn SH, Jeong WJ, et al. Clinicopathologic implications of the miR-197/ PD-L1 axis in oral squamous cell carcinoma. Oncotarget 2017;8: 66178-94.

29. Troiano G, Caponio VCA, Zhurakivska K, Arena C, Pannone G,
Mascitti M, et al. High PD-L1 expression in the tumour cells did not correlate with poor prognosis of patients suffering for oral squamous cells carcinoma: a meta-analysis of the literature. Cell Prolif 2019;52. doi: 10.1111/cpr.12537.

30. Moratin J, Metzger K, Safaltin A, Herpel E, Hoffmann J, Freier K, et al. Upregulation of PD-L1 and PD-L2 in neck node metastases of head and neck squamous cell carcinoma. Head Neck 2019;41:2484-91.

31. Pedrero JM, Carracedo DG, Pinto CM, Zapatero AH, Rodrigo JP, Nieto CS, et al. Frequent genetic and biochemical alterations of the PI 3-K/AKT/PTEN pathway in head and neck squamous cell carcinoma. Int J Cancer 2005;114:242-8.

32. Martins F, de Sousa SC, Dos Santos E, Woo SB, Gallottini M. PI3K-AKT-mTOR pathway proteins are differently expressed in oral carcinogenesis. J Oral Pathol Med 2016;45: 746-52.

33. Monteiro LS, Delgado ML, Ricardo S, Garcez F, do Amaral B, Warnakulasuriya $S$, et al. Phosphorylated mammalian target of rapamycin is associated with an adverse outcome in oral squamous cell carcinoma. Oral Surg Oral Med Oral Pathol Oral Radiol 2013;115:638-45.

34. Naruse T, Yanamoto S, Yamada S, Rokutanda S, Kawakita A, Kawasaki G, et al. Anti-tumor effect of the mammalian target of rapamycin inhibitor everolimus in oral squamous cell carcinoma. Pathol Oncol Res 2015;21:765-73.

35. Li SH, Chien CY, Huang WT, Luo SD, Su YY, Tien WY, et al. Prognostic significance and function of mammalian target of rapamycin in tongue squamous cell carcinoma Sci Rep 2017; 7:8178.

36. Okkenhaug K. Signaling by the phosphoinositide 3-kinase family in immune cells. Annu Rev Immunol 2013;31:675-704. 